International Journal of Engineering \& Technology, $7(4.30)(2018) 89-93$
International Journal of Engineering \& Technology
Website: $w w w . s c i e n c e p u b c o . c o m / i n d e x . p h p / I J E T$
Research paper

\title{
A Study of Geometry Concept Mathematization Process on Blind Student Visual Imagery
}

\author{
Andriyani $^{1 *}$, Dwi Juniati ${ }^{2}$ and Ketut Budayasa ${ }^{2}$ \\ ${ }^{1}$ Departement of Mathematics Education, Universitas Ahmad Dahlan, Indonesia \\ ${ }^{2}$ Departement of Mathematics Education, Universitas Negeri Surabaya, Indonesia \\ *Corresponding author E-mail: andriyani@mpmat.uad.ac.id
}

\begin{abstract}
Mathematization is organizing activities in finding regularities, relationships, and structures using first knowledge and skills. Mathematical learning classifies mathematization become horizontal mathematization and vertical mathematization. The horizontal mathematization deals with generalizing processes, while the vertical mathematization is a form of formalizing. This research analyzes geometry concept mathematization process on blind student visual imagery. This research was an exploratory study using a qualitative approach. These subjects research were one of the sixth-grade students who experienced a total blind since fifth grade from Elementary School for exceptional children in Surabaya and one of the fourth-grade student of an Elementary School for exceptional children in Sidoarjo who was totally blind by birth. The researcher interviewed and observed subjects that carried out two times by using similar problems at two different times. The subjects are assigned to explain their thinking about the definition of the angle that they recognize in their way. The blind students grapple with imaginative ideas that translated into formal definitions. Although the formal definition of the students has not entirely fulfilled their formal mathematical definition, they have been constructed the concept of the angle through mind experiments and sought to give the imagined the angle with their visual limitations.
\end{abstract}

Keywords: Blind Student; Concept; Mathematization; Process; Visual Imagery.

\section{Introduction}

The national education system faces a complex challenge in preparing the quality of human resources that can compete in the globalization era. Today, the main problem in formal education is the low absorption of students visible from student learning outcomes. Many students memorize of concepts, not understanding qualitative concepts or bases related to facts and knowledge relation so that students are unable to relate what they learn to how the knowledge applied in new situations.

Mathematics as a ride for education has a high potential for the tendency for memorized by students. It caused by the immateriality of objects in mathematics which would be a challenge for students to learn. In mathematics learning, students' knowledge consistently constructed using deductive logic will be constructed through an internalization process. The constructed knowledge is synthetic a priori whose existence depends on experience. Therefore, the process of developing concepts and problem-solving in the learning of mathematics can attribute to a phenomenon once experienced by students or informal knowledge of previous students, known as mathematization [1].

According to [2], mathematization refers to various ways of organizing activities related to mathematical characteristics: generality, certainty, exactness, and brevity. If the learning of mathematics contains activities related to these characteristics, then levelraising as a process of improvement and development mathematical ideas gradually can develop. An activity at a particular stage will be the subject matter in the next level or an operational matter at a particular stage will develop into the subject matter at a higher level. So mathematization is not merely a process of making phe- nomenon into mathematics. In line with the opinion of [3] which states, that mathematization is not just a unified whole process in finding and constructing a mathematical concept relevant to a phenomenon, but more important is as a level-raising.

Regarding Freudenthal's view, De Lange (in [4]) defines mathematization as organizing activities in finding regularities, relationships, and structures using first knowledge and skills. In general, mathematics in mathematical learning includes mathematical horizontal and vertical mathematization. Horizontal mathematization deals with generalizing processes that begin with an identification of mathematical concepts based on regularities and relationships found through visualization and schematization of problems. A vertical mathematization is a form of formalizing where the mathematical model obtained in horizontal mathematization becomes the foundation for the development of a more formal mathematical concept. In line with that, Murdani (in [5]) argues that vertical mathematization is an activity for formulating mathematical problems in various problem solving using some mathematical rules accordingly. The process of vertical mathematization does not occur sequentially or after the whole process of horizontal mathematization occurs intact, but both processes of mathematization can occur like stairs that often happen alternately in stages.

The initial process of mathematization is the translation of realworld problems into mathematical problems, then the use of mathematical concepts and skills mastered by students to translate the results of translation into more abstract mathematical symbols. The last stage is the reflection of the process and the results of mathematization by interpretation and validation of the results.

The process of horizontal mathematization to vertical mathematization is not simple and easy to do by students who are at concrete operational stage or students who have limited development of a 
concept, because in this process students need formal deductive thinking ability to rediscover mathematical concepts. One of the students who have limitations in developing his conception is blind students. Loss of vision in the blind has an impact on the development of cognition, especially the formation of concepts through sensory experiences to perceive the environment. According to Lowenfield (in [6]), an essential distinction between blind and sight students is the development of blind people conceptions in visualizing objects through tactual experience, while sight students through visual experiences.

Furthermore, [7] states that the development of conception in the blind depends on the level of blindness and age of blindness. In line with [8] opinion that there are differences in perceptions of a person who is blind from birth and sudden vision loss. A person who has lost sight suddenly or has had a visual experience before blind can use the experience to develop the concept their learns. By contrast, someone who are blind by birth will be more dependent on their tactual ability to learn.

According to [9], students with visual impairment will mainly depend on tactile learning methods. The tactile representation of blind students can be maps, diagrams, graphs, chard, pictures and mathematical construction. Although tactile on the blind can be used as a substitute for the eye to explore the environment, the sense of touch has limitations in range, distance, and size so that the introduction of blind students to an object is often incomplete, that is causing the tendency of blind student learning to verbalize. They tend to have verbal delusions about a thing, though the imagined is not experienced or seen directly. The imagery of something that does not exist during the process of imagining is commonly called imagery. For blind students who are suddenly blind, it is still possible to do visual imagery because he has received visual information stored in his memory.

Geometry is a branch of mathematics that in the learning uses many physical models to understand and explain a concept with measurement of length, surface area and volume [10]. In mathematics learning, from the outset, students have a stronger background in geometry because of the environment and the object of play during its developmental stages familiar with it. However, there are still many students who regard geometry as a tricky subject because geometry has the ideal material $[11,12]$. The learning of geometrical materials is generally done with the help of visualization with the sense of sight that is not owned by the visually impaired so that many teachers have difficulty giving instructions on how to study geometry for blind students even though they use physical models [13]. The difficulty of teaching this geometry is because blind students take a long time to construct a mental representation of their spatial concept [14]. The study results [15], also show that students with visual impairments have obstacles to understanding geometry, especially about geometric images.

From the results of [16] study, it found that blind students also experience other obstacles in learning that our lack of tactical materials that make students cannot learn with tactile such as Braille book, audiobook, teaching material labeled Braille. Thus, it is clear that blind students needed support to have full access to public places, transportation, and educational opportunities [17, 18].

Although challenging, it does not mean that geometry cannot be learned and taught to the blind, because geometry is the fundamental skill that students need to understand [19]. Besides, the concepts contained in the geometry also can't be separated from mathematical concepts and other fields. The concept of angle can be one of them. Reflections from angles such as "corners," "facets or outlooks" and "shapes made by two intersecting lines" are normal terms that become open knowledge of students in their daily lives. The concept of angle exists in various fields of science such as art, architecture, engineering, physics, even in other mathematical concepts such as trigonometry and calculus. Although the prototypes of angular are present in the surrounding environment, there are still many elementary school students who mistakenly conceptualize this angle concept as stated by [20].
Viewing familiarity of angle concepts as student's natural knowledge, differences in the development of blind student conceptions, and the importance of student mathematization, so it is essential to consider the conceptualization of angles in teaching geometric concepts for the visually impaired to result from a significant transition from informal knowledge to formal mathematical concepts. In this study, we will report a case study of the process of the mathematization of students who are totally blind since school age and totally blind by birth. These total blind students do mathematization by reflecting on the mental objects that are already in their minds and revising them to build their interpretation into the formal concepts of mathematics.

\section{Methods}

This research was an exploratory study with a qualitative approach which aims to analyze geometry concept mathematization process on blind student visual imagery. The question of interviews consisted of questions about subject's thinking of geometry object that is an angle. The subjects that employed as a source of qualitative data are one of the sixth-grade students who experienced a total blind since fifth grade from Elementary School for exceptional children in Surabaya-East Java (AT) and one of the fourth-grade student of an Elementary School for exceptional children in Sidoarjo-East Java who was totally blind by birth (JJ). Data on geometry concept mathematization process on blind student visual imagery were collected using observation and the interviews that carried out two times by using similar problems at two different times. A subject is assigned to explain his thinking about the definition of the angle that his recognize in their way. The data collected from the interviews were the transcribed, classified, reduced and validated by using triangulation methods to yield credible data The credible data analyzed by using qualitative research analysis data, method, data display, interpreting, and conclusion as Miles and Huberman's statement [21].

\section{Result and Discussions}

The blind student (AT) beginning mathematization of a angles concept by identifying the characteristics of angles that are relevant to the real world object. Initially, he analogized the angle with objects that he knew in everyday life as follows:

"......... the angle is a booth, the tip of the object"

In this case, the student uses visual imagery related to a definition of an angle that is related to his experience of physical objects ever encountered. Furthermore, the student seems to seek another representation from the angle to further concretize and show what he means by manipulating two pens as a model of the angle as in the following figure 1 .

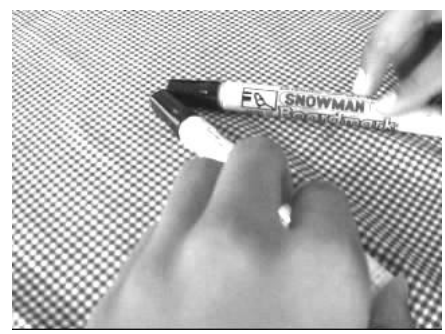

Fig. 1: Manipulative object to represent the angle by pens

The concretized of angle definition by student involves a more complex quality of a relationship between the student's self and this mathematics concept [22]. With symbolic representation through the use of manipulative objects (pens) to represent visual imagery, students have been able to find relationships and mathematical patterns that correspond to real-world problems.

When the researcher asked about the angle in the two-pen manipulation model, he showed both ends of the pen simultaneously with 
one index finger. He also uses his tactual abilities by groping along the second side of the pen in sequence from end to end to represent the angle as shown in Figure 2.

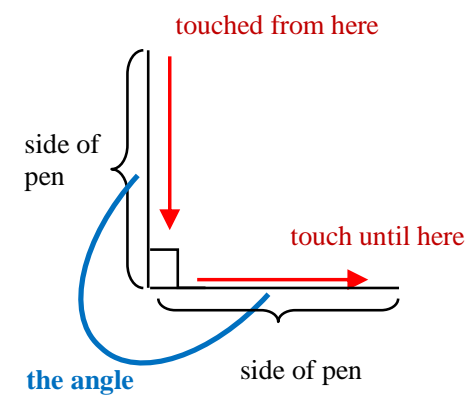

Fig. 2: Representation of the angles with blind student tactile

From these student representations, the student has been able to represent the concept of angle in different ways, including organizing angle concept according to relevant mathematical concepts and formulating mathematical assumptions. Although his two representations related to the above angle are still inconsistent, the student already understands that the angle is the shape which occurs when two rays intersected at a common point. He also uses the manipulative object to describe a unique angle (acute angle) to describe the angle generally. That is, the student still uses inductive thinking patterns or see the generality through the specificity for interpreting the angle as a thought experiment. The above activities are a form of the horizontal mathematization of student relating to open knowledge and intuition [23].

Next, the researcher asks students to explain the meaning of his two angular representations. The student explains that his first representation which is the tip-end of the pens is a part of the angle located at the end of the vertex, whereas his second representation which is two sides of the pen is the angle. The angle model manipulated by the student is unperfect, the two ends of the pen do not show the vertex, because the manipulative objects used are 3-D objects that have a thickness so that the designated vertex model is the point outside the angle. After touching the manipulative object, the student realizes that there is an incompatibility between the external representation of the manipulative object that his demonstrating with his visual imagery, so he corrected his statement about angle and vertex by pointing to the point of intersection of two pens within the interior of angle as a vertex as in the following figure 3 .

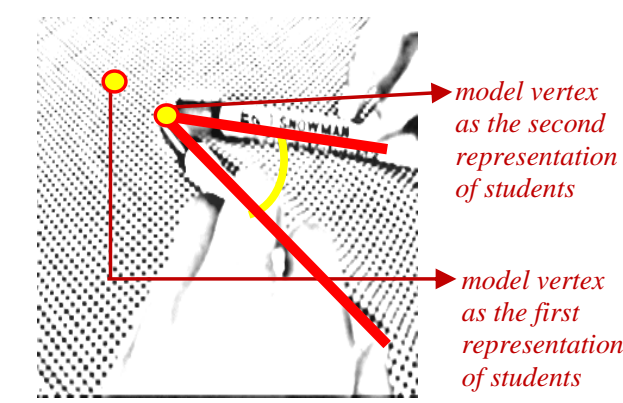

Fig. 3: Representation of vertex of the angle

The student explained again that the second representation of angle as in Figure 2 is two lines connected to construct an angle and these lines are said to be angular lines as follows:

"The angle is connected by two lines. That lines are lines that form the angle of ${ }^{\prime \prime}$

After translating the real problem (pen), the student uses mathematical concepts and skills through several different representations to make adjustments and development toward mathematical formalization. The reconstruction of verbal representations and his symbolic representations seems. The student's verbal explanation also indicates that the student has been able to provide mathemati- cal arguments related to the understanding of the angle and interrelations of angular elements. Although in his verbal representation lack the complete explanation of the position of the angle forming lines, but the symbolic representation related to the manipulation of two pens have shown about the position of the two lines that intersects at one point. Student activities in the process of reorganizing the knowledge that has obtained in the abstract language of mathematics above is a form of the vertical mathematization of students that occur sequentially and gradually with horizontal mathematization.

In addition to manipulating two pens to represent his visual imagery about angles, the student also showed two adjacent lines intersecting at one point to represent the angles in the square drawing that they made as in figure 4 .

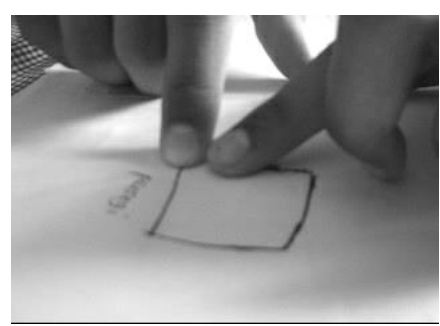

Fig. 4: Representation of the angle in AT's subject drawing

The meaning of subject interpretation when designating two adjacent lines that intersect at one point is the angle that occurs from two lines, while the intersection point of the two lines is interpreted as the end of an area in the angle located between two angular forming lines. From this explanation, it is actually seen that the subject has understood the notion of angle as a wake that occurs from two line rays that meeting each other or intersecting on the same base point.

In contrast, the blind student (JJ) beginning mathematization of a angles concept by directly explaining their interpretation of angles by using their own language as follows:

"Ehm ... An angle is the meeting of two lines at the end"

Furthermore, the student seems to seek another representation from the angle to further concretize and show what he means by manipulating two fingers as a model of the angle as in the following figure 5 .

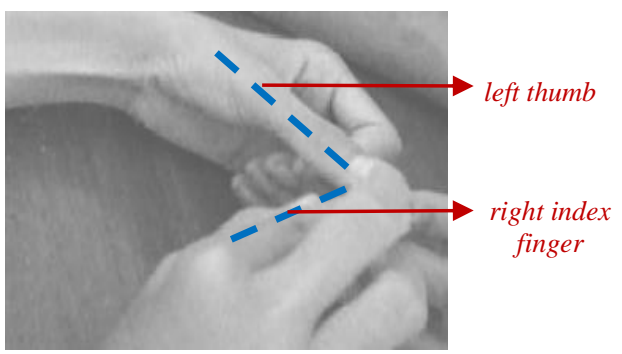

Fig. 5: Manipulative object to represent the angle by fingers

The concretized of angle definition by student involves a more complex quality of a relationship between the student's self and this mathematics concept. With symbolic representation through the use of manipulative objects (fingers) to represent visual imagery, students have been able to find relationships and mathematical patterns that correspond to real-world problems.

When the researcher asked about the angle in the two-finger manipulation model, he knocked both of his fingertips together. He also uses his tactual abilities by groping along the sides of his two fingers alternately from one fingertip to the other to represent the angle as shown in Figure 2

From the representation of this student, students have been able to represent the concept of angles in different ways, including organizing angle concept according to relevant mathematical concepts and formulating mathematical assumptions. Although his two representations related to the angle above are still inconsistent, the 
student already understands that angle is the shape which occurs when two rays intersected at a common point. He also uses the manipulative object to describe a unique (right angle) to describe the angle generally. That is, the student still uses inductive thinking patterns or see the generality through the specificity of interpreting the angle as a thought experiment. The above activities are a form of the horizontal mathematization of student relating to open knowledge and intuition.

Next, the researcher asks students to explain the meaning of his two angular representations. The student explains that the first representation or both are angles. The angle model manipulated by the student is unperfect, the two fingertips do not show the vertex, because the manipulative objects used is 3-D objects that have a thickness so that the designated vertex model is the point outside the angle.

The student uses mathematical concepts and skills through several different representations to make adjustments and development toward mathematical formalization, although not consistent. Students' verbal explanation also shows that students have been able to provide mathematical arguments related to his understanding of angle. Although the verbal representation is lacking in complete and inconsistent explanations, symbolic representations related to two-finger manipulation have shown one of its understandings of angles as two lines intersecting at one point. Student activity in the process of knowledge reorganization that has been obtained in the abstract mathematical language above is a form of students' vertical mathematization that occurs sequentially and gradually with horizontal mathematization.

In addition to manipulating two pens to represent his visual imagery about angles, the student also showed two adjacent lines intersecting at one point, or a point to represent the angles in the square drawing that they made as in figure 6.

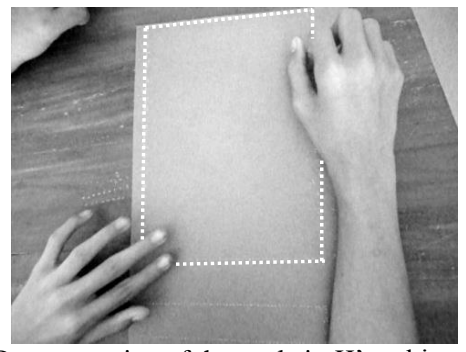

Fig. 6: Representation of the angle in JJ's subject drawing

Explicitly, the definition of the angle that both of students find does not fully satisfy the formal definition of angle as the shape formed by two rays, this rays called the lines of the angle, a common endpoint called the vertex of the angle. However, he was able to construct formal definitions and try more complex tasks than merely remembering definitions. He uses his daily language and metaphors to explain his visual imagery. The relationship between tactile and verbal involves active construction. Students have constructed a robust process-based knowledge structure on a continuous basis and involved the encapsulation of processes as objects to aid their understanding of concepts. The construction of a meaning of this knowledge through empirical abstraction (focusing on the object and its nature) and pseudo-empirical abstraction (focusing on action on objects) as presented by [24]. Furthermore, reflective abstractions will occur through mental action on mental concepts [25].

From the external representation that shows the visual imagery both of blind students above, it is known that blind students can still represent the angle well and use cognitive mechanisms that are not much different from sighted students even though the blind students lose their visualization as stated by [26]. The mathematization process carried out by blind students also shows that the brain networks for their advanced mathematical reasoning can develop even though without visual experience such as research results [27].
The visual imagery from both of blind students does have a difference, where students are totally blind after school age, they still use visual experiences that have been obtained in relation to realworld objects such as corners of the room and the ends of objects that they often encounter to be associated with the concept of angles. This is in accordance with the research from [28], which states that the perception and concept development of students totally blind after school age is influenced by their experiences before total blindness. According to [29], students totally blind after school age still have a memory about object or image prototypes that affect the perception of their geometrical object. Visual experiences that have been received by students totally blind after school age can affect the representation through their touch. This can be seen from the correction of student's statements about angle after using his tactual abilities to examine the manipulative objects that his represent as angles as in Figure 3. In line with this, in the research results [30] also suggests that there are differences in spatial imaging skills between totally blind students after school age and by birth.

\section{Conclusion}

This case study expressed blind students who grapple with their imaginative ideas on visual imagery that translated into formal definitions. He constructed the concept of the angle through mind experiments that not only responded to the syntax of the definition but also sought to give the imagined meaning to the definition of the angle. Their first undertook a series of horizontal mathematization beginning with previously open knowledge and manipulation of real objects using his tactile until the transformation process in mathematical language, and then they are doing vertical mathematization to reorganize the acquired mathematical knowledge into more abstract mathematical languages or symbols with their terms. Although, the formal definition of the student has not entirely fulfilled his formal mathematical definition, with visual limitations they have tried more complex tasks to construct definitions than remember of definitions. The mathematization process in the visual imagery of student is totally blind after school age is more complete than a totally blind student by birth because he has had a visual experience that influences his perception and tactual representation..

\section{Acknowledgement}

The author thanks Department of Magister of Mathematics Education, Faculty of Postgraduate, Universitas Ahmad Dahlan for the funding of cost of publication for this research.

\section{References}

[1] Deniz O \& Uygur-Kabael T (2017), Students' mathematization process of the concept of slope within the Realistic Mathematics Education. H.U. Journal of Education 32, 123-142.

[2] Loc NP \& Hao MH (2016), Teaching mathematics based on "Mathematization" of theory of Realistic Mathematics Education: A study of the linear function $\mathrm{Y}=\mathrm{Ax}+\mathrm{B}$. The International Journal Of Engineering And Science (IJES) 5, 20-23.

[3] Frudenthal H, Revisiting mathematics education China lectures, Kluwer Academic Publishers, (2002).

[4] Pratomo SI (2017), The correlation between student's mathematization and mathematical disposition in implementing generative learning. International Journal of Education 9, 157-164.

[5] Wardono, Mariani S, Hendikawati P \& Ikayani (2017), Mathematizing process of Junior High School students to improve mathematics literacy refer PISA on RCP learning. Journal of Physics: Conf. Series 82, 1-6.

[6] Zheng X, A study on blind students' experience of provision and support in schools (Department of Special Needs Education Faculty of Educational Sciences, University of Oslo Unpublished: Master's Dissertation), (2014). 
[7] Dick T \& Kubiak E (1997), Issues and aids for teaching mathematics to the blind. The Mathematics Teacher 90, 344-349.

[8] Percival J \& Hanson J (2007), I don't want to live for the day any more: visually impaired people $\mathrm{s}$ access to support, housing, and independence. British Journal of Visual Impairment 25, 51-67.

[9] Farrell M, The Effective Teachers" Guide to sensory impairment and physical disability practical strategies, Routledge, (2006).

[10] Hwang W-Y, Su J-H, Huang Y-M, \& Dong J-J (2009), A study of multi-representation of geometry problem solving with virtual manipulatives and whiteboard system. Educational Technology \& Society 12, 229-247.

[11] Afthina H, Mardiyana \& Pramudya I (2017), Think pair share using Realistic Mathematics Education approach in geometry learning. Journal of Physics: Conf. Series 895, 1-6.

[12] Bhagat KK \& Chang C-Y (2014), Incorporating geogebra into geometry learning-a lesson from India. Eurasia Journal of Mathematics, Science \& Technology Education 11, 77-86

[13] Pritchard CK \& Lamb JH (2012), Teaching geometry tovisually impaired students. Journal of Mathematics Teacher 106, 22-27.

[14] Thinus-Blanc C \& Gaunet F (1997), Space representations in the blind: vision as a spatial sense? Psychological Bulletin 121, 20-42.

[15] Vianna CS, Barbosa, PM, Rocha DF \& Silva B, Teaching geometry for blind and visually impaired students. International Congress on Mathematical Education, (2006).

[16] Argyropoulos V \& Stamouli M (2006), A collaborative action research project in an inclusive setting: assisting a blind student. British Journal of Visual Impairment 24, 128- 134.

[17] Gray C (2008) Support for children with a visual impairment in Northern Ireland: the role of the rehabilitation worker. British Journal of Visual Impairment 26, 239-254.

[18] Gentle F (2008), Insights from six blind Australian women. British Journal of Visual Impairment 26, 99-108.

[19] Abdullah AH \& Zakaria E (2013), The effects of Van Hiele's phases of learning geometry on student's degree of acquisition of Van Hiele levels. Procedia Social and Behavioral Sciences 102, 251-266.

[20] Devichi C \& Munier V (2013), About the concept of angle in Elementary School: misconceptions and teaching squences. Journal of Mathematical Behavior 32, 1-19.

[21] Miles MB \& Huberman AM, Qualitative data analysis: an expanded sourcebook $2^{\text {nd }}$ edition, Sage Publication, (1994).

[22] Wilensky U, Abstract meditations on the concrete and concrete implications for mathematics education. In I. Harel \& S. Papert (Eds.) Constructionism, Ablex Publishing Corporation, (1991).

[23] Laurens T, Batlolona FA, Batlolona JR \& Leasa M (2018), How does Realistic Mathematics Education (RME) improve students' mathematics cognitive achievement? Eurasia Journal of Mathematics, Science \& Technology Education 14, 569-578.

[24] Tall DO, Thomas M, Davis G, Gray EM \& Simpson A (2000), What is the object of the encapsulation of a process? Journal of Mathematical Behavior 18, 1-19.

[25] Pinto MMF \& Tall DO, Student constructions of formal theory: giving and extracting meaning. Proceedings of the Twenty third International Conference for the Psychology of Mathematics Education, 2, (1999), 41-48.

[26] Cattaneo Z, Vecchi T, Cornoldi C, Mammarella I, Bonino D, Ricciardi E \& Pietrini P (2008), Imagery and spatial processes in blindness and visual impairment. Neuroscience \& Biobehavioral Reviews 32, 1346 1360.

[27] Amalric M, Denghien I \& Dehaene S (2018), On the role of visual experience in mathematical development: evidence from blind mathematicians. Developmental Cognitive Neuroscience 30, 314-323.

[28] Andriyani, Budayasa I K \& Juniati D (2018), The blind student's interpretation of two-dimensional shapes in geometry. Journal of Physics: Conference Series 947, 1-6.

[29] Theurel A, Frileux S, Hatwell Y \& Gentaz E, The haptic recognition of geometrical shapes in congenitally blind and blindfolded adolescents: is there a haptic prototype effect? PLOS ONE 7, 6, (2012), available online: https://journals.plos.org/plosone/article? $\mathrm{id}=10.1371$ /journal.pone.0040251, last visit: 20.07.2018.

[30] Tapan K, Gandhi, Ganesh S \& Sinha P (2014). Improvement in spatial imagery following sight onset late in childhood. Psychology Science 25, 693-701. 